\title{
Samsun İlinde SPI ve PNI Kuraklık İndekslerinin Eğilim Analizi
}

\section{Trend Analysis of SPI and PNI Drought Indices in Samsun City}

\author{
Neslihan Beden 1무, Vahdettin Demir ${ }^{2}{ }^{(0)}$, Aslı Ülke Keskin ${ }^{3 *(C)}$ \\ ${ }^{1}$ Samsun Üniversitesi, Kavak Meslek Yüksekokulu, İnşaat Bölümü , Samsun, TÜRKIYE \\ ${ }^{2}$ KTO Karatay Üniversitesi, Mühendislik Fakültesi, İnşaat Mühendisliği Bölümü, Konya, TÜRKIYY \\ ${ }^{3}$ Ondokuzmayıs Üniversitesi, Mühendislik Fakültesi, İnşaat Mühendisliği Bölümü, Samsun, TÜRKIYE \\ Sorumlu Yazar / Corresponding Author*: asli.ulke@omu.edu.tr
}

Atıf șekli/How to cite: BEDEN, N., DEMIR, V., KESKIN, A.Ü. (2020). Samsun İlinde SPI ve PNI Kuraklık İndekslerinin Eğilim Analizi. DEUFMD $22(64), 107-116$

$\ddot{0} \mathbf{z}$

Kuraklık ekosistemleri ve toplumu birçok yönden etkileyen karmaşık bir doğal tehlikedir. Meteorolojik değişkenliğin bir sonucu olan kuraklığın etkilerini hafifletmek için su kaynakları yönetim stratejilerinin geliştirilmesi ve kuraklı riskinin değerlendirilmesi gereklidir. Su kaynaklarının planlamasında ve yönetiminde kuraklıkların tanımlanması, izlenmesi ve karakterizasyonu büyük önem tașımaktadır. Kuraklığın belirlenmesinde kullanılan yöntemlerden biri yağış değerleri yardımıyla bulunan kuraklık indeksleridir. Bu çalışmada, Samsun ili Meteoroloji Gözlem İstasyonu (17030-MGİ) 1960-2015 yılları arası kaydedilen aylık toplam yağış değerleri (mm) kullanılarak kuraklık analizi iki aşamada incelenmiștir. İlk aşamada kuraklık indekslerinden; Standart Yağıș İndeksi (SPI) ve Normalin Yüzdesi İndeksi (PNI) değerleri bulunmuştur. İndeks değerlerinin geçmişteki davranışını inceleyip, gelecekteki davranışının nasıl olacağını tahmin etme, uzun süreli kuraklığın tespit edilmesi için önemlidir. Bu amaçla da çalışmanın ikinci aşamasında, elde edilen indeks değerlerine eğilim analizi (Mann-Kendall yöntemi) uygulanmıştır. İlk aşamanın sonuçları incelendiğinde, her iki yönteme göre de normal ve normale yakın kuraklık belirtisine rastlanmıştır. İkinci aşamada, her iki yönteme göre de indeks değerlerinin artan yönde eğilim gösterdiği tespit edilmiştir. Fakat bu eğilimin istatistiksel olarak anlamlı olmadığı sonucuna varılmıştır.

Anahtar Kelimeler: Samsun, Kuraklık, SPI, PNI, Yağıș, Mann-Kendall

\begin{abstract}
Drought is a complex natural hazard that impacts ecosystems and society in many ways. Droughts are an inevitable consequence of meteorological variability, and the design of water resource infrastructure and management strategies to mitigate their effects requires assessment of the risk. The identification, monitoring and characterization of droughts are of great importance in water resources planning and management. One of the methods used to determine drought is the drought indexes with the help of precipitation values. In this study, Samsun Meteorological Observation Station (17030-MOS) analyzed the drought analysis in two stages using the total precipitation values (mm) recorded between 1960-2015. First stage drought indices; Standardized Rainfall Index (SPI)
\end{abstract}


and Normal Percentage Index (PNI) values were found. Examining the behavior of index values in the past and predicting how future behavior will be is important for determining long-term drought. For this purpose, the trend analysis of the index values obtained in the second phase of the study was examined using the Mann-Kendall method. When the results of the first stage were examined, both normal and normal drought symptoms were encountered. In the second step, it was determined that the index values tended to increase directions according to both methods. However, this trend was determined not to be statistically significant.

Keywords: Samsun, Drought, SPI, PNI, Precipitation, Mann-Kendall

\section{Giriş}

Bir bölgede zamanla, sıcaklık ve yağıșlarda yașanan değișiklikler insan yașamını etkileyen ve ciddiye alınması gereken önemli olaylara sebep olmaktadır. Sıcaklık değerlerinin sürekli artan eğilim göstermesi ve yağıș değerlerinin sürekli azalma eğiliminde olması sonucunda uzun süreçlerde gerçekleșen bir fenomen olan kuraklık-çölleşme olayı meydana gelmektedir. Tam tersi durumda yani yağışların sürekli artması veya anlık yağıșların sürekli artma eğilimi göstermesi taşkın ve heyelan gibi tehlikelere sebep olmaktadır. Sıcaklık değerleri ve yağış miktarları farklı dönemlerde değişimler göstersede, sanayileşmenin artması ile birlikte sıcaklıklarda artışların görülmesi ve yağış miktarlarındaki azalma ya da artma eğilimi dünyanın süregelen düzenini değiştirmektedir. Yapılan çalışmalara göre küresel iklim değişikliğinin bir sonucu olarak 1880-2012 yılları arasında ortalama yüzey sıcaklığ $0.85^{\circ} \mathrm{C}$ artmıș, yüksek enlemlerde yağıșlar artarken, düșük seviye enlemlerde ise yağıșlar azalmıștır. Bununla beraber 2020-2029 yılları arasında yüzey sıcaklıklarının yaklaşık $2^{\circ} \mathrm{C}$ artacağ öngörülmektedir [1, 2]. Meydana gelen sıcak hava dalgası olaylarından binlerce kişi etkilenmiş, hatta bazı olaylarda can kayıpları meydana gelmiștir $[3,4]$.

Kuraklık aniden meydana gelen bir olay değildir. Bir bölgede beklenenden ya da normalden daha az yağıș düşmesi sebebiyle oluşan ve kademe kademe gelișen doğal bir süreç, verdiği zarar bakımından ise bir afettir. Ayrıca tahmin edilmesi ya da hesaplanması da oldukça karmaşıktır. $\mathrm{Bu}$ olayda bağımlı değişkenler olarak sıcaklık, yağış ve toprak özellikleri sayllabilir [5].

Kuraklık, ülke ekonomisi ve gelișim kapasitesi ile halkın refah seviyesine önemli ölçüde etki edebilecek bir olaydır. Bu nedenle gelecekteki kuraklık senaryolarının değerlendirilmesi, tarım, enerji, ekoloji, biyolojik çeşitlik ormancıllk, sağllk ve su sektörleri dahil olmak üzere ulusal ekonominin birçok yönü için oldukça büyük önem arz etmektedir [6]. Oğuztürk ve Yıldız çalıșmalarında, Kırıkkale İli'nde çeşitli zaman periyotları için $(1,3,6,9,12$ ve 24 aylık) kuraklık analizi yapmışlardır. $\mathrm{Bu}$ amaçla Kırıkkale meteoroloji istasyonda 1950 ile 2007 yılları arasındaki 58 yıllık döneminin aylık yağıș verilerine SPI metodu uygulanarak, bu değerlerin seçilen farklı zaman dilimlerindeki kuraklık özellikleri incelenmiştir. Çalışmada kuraklık genliği, süresi ve şiddeti farklı zaman dilimlerinde hesaplanarak, tespit edilen kuraklığın su kaynaklarına etkisi incelenmiștir [7]. Selçuk, Kızılırmak Havzasına ait hidrolojik ve meteorolojik verileri kullanarak havzanın kuraklık durumunu standart yağış indisi (SPI), ve akım kuraklık indisi (SDI) kullanarak analiz etmiş, çalışma sonucunda her iki yöntemin uyumlu sonuçlar gösterdiğini ortaya koymuştur [8]. Hezarani, 1970-2014 yılları arasında Yeşilırmak Havzasındaki kuraklık durumunu belirlemek için SPI, PNI kuraklık indislerini kullanmıștır. İndisler yağıș verilerinin yanında akım verilerine de uygulanmı ve kuraklık haritaları elde edilmiștir. Kuraklık indisleri 1, 3, $6,12,24,36$ ve 48 ayllk zaman dilimlerinde incelenmiștir ve havzanın iç kesimlerindeki kuraklığın kıyı kesimlere göre daha fazla olduğu sonucuna varılmıștır [9]. Osuch ve ark., Polonya'da iklimlerin değișimini tahmin etmek için SPI yöntemini kullanmıştır. Altı farklı iklim projeksiyonu araştırdığı çalıșmada 1-3-6-12 ve 24 aylık yağıș verileri kullanmıștır. Ayrıca SPI değerlerini eğilim analiz yöntemlerinden MannKendall ve Sen'in eğilim yöntemlerini kullanarak incelemiş ve haritalandırmıştır. Haritalar incelendiğinde, yaz aylarında önemli artışların olduğunu belirtmiştir [6]. Wang ve ark., Çin'in kuzeybatı bölgesinde 1960'dan 2010'a kadar olan günlük sıcaklık ve yağıș verilerini kullanarak, iklim endekslerinin eğilimi ve ani değişimini incelediği çalışmalarında tüm sıcaklık indekslerinin istatistiksel olarak önemli bir artış 
gösterdiğini belirtmişlerdir[11]. Konuya ilișkin olarak, Uluslararası İklim Değișikliği Paneli (International Panel of Climate Change-IPCC) raporları ve çok sayıda bilimsel makale; kuraklık olaylarının iklim değișikliğinin bir sonucu olduğunu ve 20. yüzyılın sonlarında özellikle bazı bölgelerde sıklık ve yoğunluklarında artış olacağını ortaya koymaktadır [11-22]. Türkiye'nin nispeten sinırlı su kaynaklarına sahip olması nedeniyle önümüzdeki dönemlerde su ihtiyacının sağlanması konusunda zorluklar ortaya çıkabilir. Çalışma alanı olan Samsun ili ise, ülkemizde en fazla yağış alan Karadeniz Bölgesi'nin orta bölümünde yer alır ve bölgenin en gelișmiş șehridir.

$\mathrm{Bu}$ çalışmada, Samsun ili meteoroloji istasyonunun 1960-2015 yılları arası aylık toplam yağış verileri kullanılarak kuraklık analizleri Standart Yağış indeksi (SPI) ve Normalin Yüzdesi Metodu (PNI) kullanılarak incelenmiștir. Elde edilen index değerlerinin eğilim analizi ise Mann-Kendall yöntemi kullanılarak yapılmıştır. Analizler güven aralığının \%95'lik kısmında aylık, 3-aylık ve 12aylık periyotlarda ele alınmıştır.

\section{Materyal ve Metot}

Samsun ili kuraklık analizi için Meteoroloji Genel Müdürlüğü (MGM)'nden alınan Samsun istasyonuna ait aylık toplam yağış verileri kullanılmıştır. Çalışmada 1960-2015 periyodunda gözlemlenmiş aylık yağış verileri kullanılanmiştır. Samsun istasyonu Orta Karadeniz Bölümü'nde, 22 No'lu Doğu Karadeniz Havzası'nda yer almaktadır. Samsun Meteoroloji istasyonuna ait konum bilgileri ve istatistiksel bilgiler Tablo 1'de verilmiștir.

Tablo 1. Samsun istasyonuna ve yağış verilerine ait istatistiksel bilgiler

\begin{tabular}{ll}
\multicolumn{2}{c}{$\mathbf{1 7 0 3 0}$-Samsun Meteoroloji İstasyonu } \\
\hline Enlem & $41^{\circ} 21^{\prime} \mathrm{K}$ \\
Boylam & $36^{\circ} 14^{\prime} \mathrm{D}$ \\
Yükseklik & $4 \mathrm{~m}$ \\
Veri Periyodu & $1960-2015$ \\
Veri sayısı & 672 \\
Maksimum & 350,3 \\
Minimum & 0 \\
Ortalama & 58,866 \\
Standard sapma & 8,978 \\
Çarpıklık katsayısı & $+0,583$ \\
\hline
\end{tabular}

Çalışma alanı Şekil 1'de gösterilmiştir.

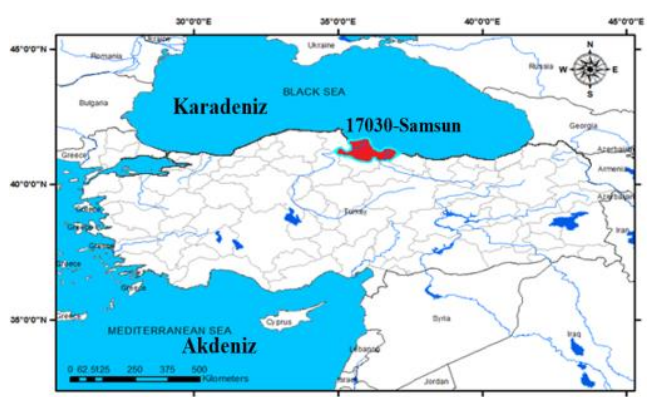

Şekil 1. Çalışma alanı

Tablo 1'de verilen istatistik bilgilere göre, aylık ortalama toplam yağıș miktarının $58,866 \mathrm{~mm}$, aylık maksimum toplam yağış miktarının da $350,3 \mathrm{~mm}$ olduğu görülmektedir. İstasyonda 56 yıl için toplam 672 adet veri bulunmaktadır.

\subsection{Normal dağılım}

Kuraklık analizine geçilmeden önce yağış verilerine normal dağılım uygulanmıştır. Gauss dağılımı olarak da bilinen normal dağılımın olasılık yoğunluk fonksiyonu Denklem 1'de yer almaktadır.

$$
F(x)=\frac{1}{\sigma \sqrt{2 \pi}} \exp \left(-\frac{(x-\mu)^{2}}{2 \sigma^{2}}\right)
$$

Dağılımın $N\left(\mu, \sigma^{2}\right)$ şeklinde gösterilen iki parametresinden, $\mu_{\mathrm{x}}$ rastgele değişkenlerin ortalamasını, $\sigma$ ise standart sapmasını ifade etmektedir [23].

\subsection{Standart yağış indeksi (SPI)}

Standart Yağış İndisi (SPI), Mckee ve ark. tarafından (1993) yılında önerilmiştir ve iklimin değişkenlik gösterdiği bölgelerde, kuraklığı tanımlamak ve izlemek amaciyla kullanılmaktadır. SPI analizi yağış verisinin normal, log-normal ve gamma olasilık dağılımlarına uygunluk durumuna göre gerçekleştirilmektedir [24]. Veriler normal dağılmış ise yağışın belirli bir zamandaki ortalama değerden farkının, standart sapmaya bölünmesiyle bölgelerdeki anormallikler belirlenebilir. $\mathrm{Bu}$ yöntem Denklem 2'de verilmiştir.

$$
S P I=\frac{\left(x_{i}-x_{i}^{\text {ort }}\right)}{\sigma}
$$


Denklem 2'de $x_{i}$; aktüel yağıș miktarını ve $x_{i}$ ort ; ortalama yağıș miktarını ve $\sigma$; standart sapmayı göstermektedir [25]. SPI sonuçlarına göre yapılan sınıflandırma Tablo 2'de verilmektedir.

Tablo 2. SPI değerlerine göre indeks değerleri ve sinıflandirma [25]

\begin{tabular}{ll} 
SPI dĕgerleri & Sınıflandırma \\
\hline$>2$ & Çok şiddetli yağışlı \\
$1,50 \sim 1,99$ & Çok yağışlı \\
$1,00 \sim 1,49$ & Orta şiddetli yağışlı \\
$0,99 \sim 0$ & Normal \\
$0 \sim-0,99$ & Normale yakın kuraklık \\
$-1,00 \sim-1,49$ & Orta şiddetli kuraklık \\
$-1,50 \sim-1,99$ & Şiddetli kuraklık \\
$<-2$ & Çok şiddetli kuraklık \\
\hline
\end{tabular}

SPI değerlerine göre kuraklık değerlendirmesi yapıldığında indeksin sürekli negatif değer aldığı zaman periyodu kurak dönem olarak tanımlanabilir. İndeksin sıfırın altına düştüğü ilk dönem kuraklığın bașlangıcı kabul edilirken, indeksin pozitif değer aldığı ay kuraklığın bitimi olarak nitelendirilir [25].

\subsection{Normalin yüzdesi indeksi (PNI)}

Normalin yüzdesi indeksi (PNI), belirlenen bir zaman dilimi içerisindeki yağıș miktarı, ortalama yağışa bölünerek elde edilir ve birimi yüzdedir. Zaman serisinin 12 ay veya daha az olduğu periyotlar için PNI yöntemi kullanılabilir [26]. Bu yöntem Denklem 3'te verilmiştir.

$$
P N I=\frac{\left(x_{i}\right)}{x_{i}^{\text {ort }}} \times 100
$$

Denklem 3'te yer alan PNI; normalin yüzdesi indeksi, $\mathrm{x}_{\mathrm{i}}$; aktüel yağış miktarını ve $\mathrm{x}_{\mathrm{i}}{ }^{\text {ort }}$; ortalama yağıș miktarını göstermektedir. PNI sonuçlarına göre yapılan sınıflandırma Tablo 3 'de yer almaktadır.

Tablo 3. PNI değerlerine göre indeks değerleri ve sinıflandırma [26]

\begin{tabular}{cllll}
\hline Periyot & $\begin{array}{l}\text { Normal } \\
\text { ve Üzeri }\end{array}$ & $\begin{array}{l}\text { Hafif } \\
\text { Kurak }\end{array}$ & $\begin{array}{l}\text { Orta } \\
\text { Siddette } \\
\text { Kurak }\end{array}$ & $\begin{array}{l}\text { Şiddetli } \\
\text { Kurak }\end{array}$ \\
\hline 1 & $>75$ & $65-75$ & $55-65$ & $<55$ \\
3 & $>75$ & $65-75$ & $55-65$ & $<55$ \\
6 & $>80$ & $70-80$ & $60-70$ & $<60$ \\
9 & $>83,5$ & $73,5-83,5$ & $63,5-73,5$ & $<63,5$ \\
12 & $>85$ & $75-85$ & $65-75$ & $<65$ \\
\hline
\end{tabular}

Tablo 3'e göre indeks değerinin gözlenen periyoda göre verilen eșik değerin altına düştüğü zaman periyodu kurak dönem olarak tanımlanır. Örneğin eşik değer 12 aylık periyot için indeks değerinin \%85'in altında olma durumudur. PNI'nın eşik değerin altına düştüğü ilk değer kuraklığın başlangıcı olarak, eşik değeri aştığı değer ise kuraklığın bitimi olarak tanımlanır.

\subsection{Mann-Kendall eğilim analizi (MK)}

Mann-Kendall istatistiği "S" hesaplandıktan sonra aşağıda yer alan Denklem 4-7 kullanılarak MK "Z" değeri hesaplanır. Hesaplanan Z değeri de belirlenen olasılık anlamlılık düzeylerine göre normal dağılım çizelgesindeki standart $\mathrm{Z}$ değerleriyle karşılaştırılır [27, 28].

$$
\begin{aligned}
& \operatorname{sgn}\left(x_{j}-x_{i}\right)=\left(\begin{array}{ccc}
1 ; & \text { Ĕger } & x_{j}>x_{i} \\
0 ; & E \breve{g} e r & x_{j}=x_{i} \\
-1 ; & E \breve{g} e r & x_{j}<x_{i}
\end{array}\right. \\
& S=\sum_{i=1}^{n-1} \sum_{j=i+1}^{n} \operatorname{sgn}\left(x_{j}-x_{i}\right) \\
& \operatorname{Var}(S)=\frac{n(n-1)(2 n+5)-\sum_{i=1}^{p} t_{i}\left(t_{i}-1\right)\left(2 t_{i}+5\right)}{18} \\
& Z=\left(\begin{array}{ccc}
\frac{S-1}{\sqrt{\operatorname{Var}(S)} ;} & \text { Ĕger } & S>0 \\
0 ; & \text { Ĕer } & S=0 \\
\frac{S+1}{\sqrt{\operatorname{Var}(S)} ;} ; & \text { Ĕger } & S<0
\end{array}\right.
\end{aligned}
$$

Normal dağılımda anlamlılık, genellikle 0.05 $(\alpha=\% 5)$ olasılığına sahip çift yönlü güven aralıkları ile öngörülmektedir. Hesaplanan Z değeri, dağılım çizelgesindeki $\mathrm{Z}_{1-\alpha / 2}$ değerinden küçük olduğu durumlarda sıfır hipotezi $\left(\mathrm{H}_{0}\right)$ kabul edilmektedir ve zaman serisinde istatistiksel olarak anlamlı bir eğilimin olmadığı sonucuna varılmaktadır. Tersi durumda, hesaplanan $\mathrm{Z}$ değeri, dağılım çizelgesindeki $Z_{1-\alpha / 2}$ değerinden büyük olduğu durumlarda da sıfır hipotezi $\left(\mathrm{H}_{0}\right)$ kabul edilmemekte ve zaman serisinde eğilimin varlığ varılmaktadır. S'nin pozitif veya negatif değer alması durumuna göre de eğilimin artan veya azalan yönde olduğu söylenebilir. Hesaplanan S değeri pozitif ise, incelenen olayda artan yönde, negatif ise azalan yönde bir eğilim olduğu sonucuna varılmaktadır [29]. 


\section{Bulgular}

Çalıșma iki așamada incelenmiș olup, ilk aşamada 1, 3 ve 12 aylık SPI ve PNI kuraklık indeksleri hesaplanmış ve karşılaştırılmıștır. İkinci aşamada, kuraklık indekslerinin eğilimi Mann-Kendall eğilim analizi \%95 güven aralığında gerçekleştirilmiștir. Kuraklık indekslerinin hesabında verilerin normal dağılıma uygunluğu Kolmogorov Smirnov testi ile incelenmiştir [30, 31]. Testte güven aralığının \%95'lik kısmında veya \%5 önem seviyesinde elde edilen test istastistiği $\mathrm{P}$ değerleri $\mathrm{P}$ kritik değerlerle karşılaştırılmıştır [32]. Elde edilen P değerlerinin $P$ kritik değerden küçük olduğu görülerek kuraklık indisleri hesaplanmıștır. Toplamda 56 veri için P kritik değeri 0,181 olup çalışılan aylar, mevsimler ve yıllık değerlendirme için elde edilen test değerleri Tablo 4'de verilmiștir.

Tablo 4. P test değerleri

\begin{tabular}{ll}
\hline Periyot & P test \\
\hline Ocak & 0,114 \\
Şubat & 0,167 \\
Mart & 0,067 \\
Nisan & 0,117 \\
Mayıs & 0,113 \\
Haziran & 0,110 \\
Temmuz & 0,141 \\
Ağustos & 0,180 \\
Eylül & 0,108 \\
Ekim & 0,178 \\
Kasım & 0,112 \\
Aralık & 0,103 \\
Kış & 0,086 \\
İlkbahar & 0,103 \\
Yaz & 0,112 \\
Sonbahar & 0,069 \\
Yllık & 0,055 \\
\hline &
\end{tabular}

Tablo 4 incelendiğinde $\mathrm{P}<\mathrm{P}_{\text {kritik }}$ olduğundan yağıș verileri kuraklık analizi için normal dağılıma uymaktadır ve denklem 2'in uygulanabilirliğini göstermektedir [33].

\subsection{Standart yağış indeksi (SPI) ve normalin yüzdesi (PNI) sonuçları \\ 3.1.1. 12-Aylık değerlendirme}

Çalışmada 1960-2015 yılları arası 56 yıl için hesaplanan indeks değerlerinin verilmesinin karmaşık ve toplam sayfa sayısını zorlaması nedeniyle çalışmada kuraklığın gözlemlendiği yıllar verilmiş, tüm yıllara ait indeks dağılımları ise yüzdesel olarak verilmiştir. 12-aylık sonuçlar incelendiğinde; en büyük yüzdelik oranlar SPI metoduna göre "normal" değerlerde, PNI metoduna göre ise "normal ve üzeri" değerlerde olduğu görülmüştür. SPI metoduna göre "orta şiddetli kuraklı" 1986, 1982, 1979 ve 1960 yıllarında görülmüştür. Fakat yıllar incelendiğinde bu durumun sürekliliğinin olmadığı görülmüştür. SPI metoduna göre "șiddetli kuraklık" 1964, 1974, 1976 ve 1982 yıllarında görülmüştür. PNI metoduna göre 1987-2015 yılları arasında "normal ve üzeri" kuraklık belirtisi, 1964 ve 1981 yıllarında "orta şiddetli kuraklık”, 1960, 1974, 1976, 1979, 1982 ve 1986 yllarında ise "hafif kuraklık" belirtisi tespit edilmiştir. Bölüm 2.1 ve $2.2^{\prime}$ de yer alan denklemler kullanılarak SPI - PNI görülme sayıları ve oranları Tablo 5 ve Tablo 6'da verilmiștir.

Tablo 5. 12-aylık SPI metodu özet sonuçları

\begin{tabular}{lll} 
SPI Sınıfları & $\begin{array}{l}\text { Görülme } \\
\text { Sayısı }\end{array}$ & $\begin{array}{l}\text { Görülme } \\
\text { Oranı }\end{array}$ \\
\hline Çok şiddetli yağışlı & 2 & $\% 3,57$ \\
Çok yağışlı & 2 & $\% 3,57$ \\
Orta şiddetli yağışlı & 1 & $\% 1,79$ \\
Normal & 22 & $\% 39,29$ \\
Normale yakın & 21 & $\% 37,50$ \\
Orta şiddetli kuraklık & 4 & $\% 7,14$ \\
Şiddetli kuraklık & 4 & $\% 7,14$ \\
Çok şiddetli kuraklık & 0 & $\% 0,00$ \\
\hline
\end{tabular}

Tablo 6. 12-aylık PNI metodu özet sonuçları

\begin{tabular}{lll}
\hline PNI Sınıfları & $\begin{array}{l}\text { Görülme } \\
\text { Sayısı }\end{array}$ & $\begin{array}{l}\text { Görülme } \\
\text { Oranı }\end{array}$ \\
\hline Normal ve Üzeri & 48 & $\% 85,71$ \\
Hafif Kurak & 6 & $\% 10,71$ \\
Orta Şiddette Kurak & 2 & $\% 3,57$ \\
Şiddetli Kurak & 0 & $\% 0,00$ \\
\hline
\end{tabular}




\subsubsection{3-Aylık değerlendirme}

Mevsimsel düzende 3-aylık periyotlarda elde edilen sonuçlar Tablo 7 ve Tablo 8'de verilmiștir.

Tablo 7 ve 8'e göre üçer aylık sonuçlar incelendiğinde; en büyük yüzdelik oranlar SPI metoduna göre "normal ve normale yakın kuraklık" değerlerde $(\% 29,46$ ve $\% 38,84)$, PNI metoduna göre ise "normal ve üzeri" değerlerde (\%62) görülmüştür. Sonuçlar yüzdesel olarak incelendiğinde SPI yöntemine göre sonuçların \%38,84'ü "normale yakın kuraklık", \%29,46'sı "normal", \%8,04'ü "orta şiddetli yağışlı", \%4,46'sı "çok yağıșlı", \%3,57'si ise "çok șiddetli yağıșlı" olduğu görülmektedir. Kuraklığa rastlanmayan sinıflar olarak ifade edilen bu sınıfların toplam yüzdesi ise $\% 84,37$ 'dir. PNI yöntemine göre ise "hafif kuraklık" \%10, "normal üzeri kuraklık" ise \%62 'dir. Benzer șekilde kuraklığın görülmediği PNI sınıflarının toplam yüzdesi ise \%72'dir. Şiddetli kuraklık belirtisi SPI ve PNI yöntemlerine göre sirasıyla $\% 5$ ve $\% 17$ mertebesindedir. Her iki kuraklık analiz yöntemine göre en kurak ve yağışlı geçen mevsimlerin yılları; Kıș mevsimlerinde 1972 en kurak yıl, 1966 en yağışlı geçen yıl, İlkbahar mevsimlerinde 1979 en kurak yıl, 1967 en yağıșl geçen yll, Yaz mevsimlerinde 2001 en kurak yıl, 2012 en yağıșlı geçen yıl, Sonbahar mevsimlerinde 1974 en kurak yıl, 1988 en yağışlı geçen yll olarak tespit edilmiştir.

\subsubsection{Aylık değerlendirme}

Ayrıca tüm yıllara ait aylık değerlendirme, görülme sayıları ve oranları Tablo 9 ve Tablo 10 'da verilmiştir.

Tablo 8 ve 9 incelendiğinde, SPI metoduna göre $\% 49$ 'luk oranla normale yakın kuraklık, ardından \%26'lı oranla normal kuraklık belirtisi görülmektedir. Orta șiddetli kuraklık (\%9) ve şiddetli kuraklık (\%1) sinıflandırmada $\% 10$ 'luk kısımda varlığını göstermektedir. SPI metodunda siniflandirma "normal" tanımlamasından ikiye ayrilırsa (Normalde dahil) kuraklık belirtisinin olmadığı kısım $\% 41$ 'lik, kuraklık belirtisinin olduğu kısım ise \%59'luk bir kısımda yer almaktadır.

PNI metoduna göre ise, \%51'lik oranla normal ve üzeri kuraklık belirtisi, ardından \%31'lik oranla şiddetli kuraklık belirtisi gelmektedir. Sinıflar arasında genellikle benzerlik görülse de sınıf sayılarındaki farklılık sonuçların farklı gözükmesine sebep olmaktadır. SPI yöntemine benzer șekilde "normal ve üzeri" tanımlamasında sınıfların ikiye ayrıldığı varsayılırsa \%51'lik kısımda kuraklık belirtisinin olmadığı, \%49'luk kısımda ise kuraklık belirtisinin olduğu görülmektedir.

1960-2015 yılları arası her iki kuraklık yöntemine göre de en kurak ve yağışlı geçen ayların yılları; Ocak ayı için 2014 en kurak yıl, 2011 en yağıșlı geçen yıl, Şubat ayı için 1981 en kurak yıl, 1962 en yağışlı geçen yıl, Mart ayı için 1986 en kurak yıl, 2005 en yağışlı geçen yıl, Nisan ayı için 1998 en kurak yıl, 1995 en yağışlı geçen yıl, Mayıs ayı için 1979 en kurak yıl, 1986 en yağışlı geçen yıl, Haziran ayı için 2003 en kurak yıl, 1991 en yağışlı geçen yıl, Temmuz ayı için 2000 en kurak yıl, 2012 en yağıșlı geçen yıl, Ağustos ayı için 2006 en kurak yll, 2013 en yağıșlı geçen yıl, Eylül ayı için 1984 en kurak yıl, 1996 en yağıșlı geçen yıl, Ekim ayı için 1966 en kurak yıl, 1988 en yağıșlı geçen yıl, Kasım ayı için 1962 en kurak yıl, 1967 en yağışlı geçen yıl, Aralık ayı için 1960 en kurak yıl, 1966 en yağışlı geçen yıl olarak tespit edilmiştir.

Tablo 7. 3-aylık SPI metodu görülme sayıları ve oranları

\begin{tabular}{lllllll}
\hline AYLAR & Kış & İkbahar & Yaz & Sonbahar & Toplam & Oran(\%) \\
\hline Çok Şiddetli Yağıșlı & 2 & 2 & 2 & 2 & 8 & $\mathbf{3 , 5 7}$ \\
Çok Yağıșlı & 3 & 2 & 2 & 3 & 10 & $\mathbf{4 , 4 6}$ \\
Orta Şiddetli Yağıș & 3 & 6 & 2 & 7 & 18 & $\mathbf{8 , 0 4}$ \\
Normal & 19 & 15 & 19 & 13 & 66 & $\mathbf{2 9 , 4 6}$ \\
Normale Yakın Kuraklık & 20 & 22 & 25 & 20 & 87 & $\mathbf{3 8 , 8 4}$ \\
Orta Şiddetli Kuraklık & 9 & 6 & 6 & 9 & 30 & $\mathbf{1 3 , 3 9}$ \\
Şiddetli Kuraklık & 0 & 3 & 0 & 2 & 5 & $\mathbf{2 , 2 3}$ \\
Çok Șiddetli Kuraklık & 0 & 0 & 0 & 0 & 0 & $\mathbf{0}$ \\
\hline Toplam & $\mathbf{5 6}$ & $\mathbf{5 6}$ & $\mathbf{5 6}$ & $\mathbf{5 6}$ & $\mathbf{2 2 4}$ & $\mathbf{1 0 0}$ \\
\hline
\end{tabular}


DEU FMD 22(64), 107-116, 2020

Tablo 8. 3-aylık PNI metodu görülme sayıları ve oranları

\begin{tabular}{lllllll}
\hline AYLAR & Kiș & İkbahar & Yaz & Sonbahar & Toplam & Oran(\%) \\
\hline Normal ve Üzeri & 35 & 34 & 31 & 38 & $\mathbf{1 3 8}$ & $\mathbf{6 2}$ \\
Hafif Kuraklık & 5 & 10 & 4 & 4 & $\mathbf{2 3}$ & $\mathbf{1 0}$ \\
Orta Şiddetli Kuraklık & 9 & 7 & 5 & 3 & $\mathbf{2 4}$ & $\mathbf{1 1}$ \\
Şiddetli Kuraklık & 7 & 5 & 16 & 11 & $\mathbf{3 9}$ & $\mathbf{1 7}$ \\
\hline Toplam & $\mathbf{5 6}$ & $\mathbf{5 6}$ & $\mathbf{5 6}$ & $\mathbf{5 6}$ & $\mathbf{2 2 4}$ & $\mathbf{1 0 0}$ \\
\hline
\end{tabular}

Tablo 9. Aylık SPI metodu görülme sayıları ve oranları

\begin{tabular}{|c|c|c|c|c|c|c|c|c|c|}
\hline AYLAR & $\begin{array}{l}\text { Çok } \\
\text { Şiddetli } \\
\text { Yağışlı }\end{array}$ & $\begin{array}{l}\text { Çok } \\
\text { Yağışlı }\end{array}$ & $\begin{array}{l}\text { Orta } \\
\text { Şiddetli } \\
\text { Yağış }\end{array}$ & Normal & $\begin{array}{l}\text { Normale } \\
\text { Yakın } \\
\text { Kuraklık }\end{array}$ & $\begin{array}{l}\text { Orta } \\
\text { Şiddetli } \\
\text { Kuraklık }\end{array}$ & $\begin{array}{l}\text { Şiddetli } \\
\text { Kuraklık }\end{array}$ & $\begin{array}{l}\text { Çok } \\
\text { Şiddetli } \\
\text { Kuraklık }\end{array}$ & Toplam \\
\hline Ocak & 1 & 4 & 4 & 13 & 26 & 5 & 3 & 0 & 56 \\
\hline Şubat & 3 & 2 & 3 & 14 & 29 & 4 & 1 & 0 & 56 \\
\hline Mart & 2 & 1 & 4 & 20 & 21 & 3 & 4 & 1 & 56 \\
\hline Nisan & 2 & 4 & 3 & 13 & 26 & 8 & 0 & 0 & 56 \\
\hline Mayis & 4 & 1 & 3 & 15 & 26 & 7 & 0 & 0 & 56 \\
\hline Haziran & 3 & 1 & 4 & 20 & 22 & 5 & 1 & 0 & 56 \\
\hline Temmuz & 3 & 0 & 3 & 15 & 32 & 3 & 0 & 0 & 56 \\
\hline Ağustos & 2 & 2 & 5 & 9 & 38 & 0 & 0 & 0 & 56 \\
\hline Eylül & 2 & 3 & 3 & 18 & 19 & 11 & 0 & 0 & 56 \\
\hline Ekim & 3 & 3 & 3 & 10 & 31 & 6 & 0 & 0 & 56 \\
\hline Kasım & 1 & 3 & 2 & 16 & 27 & 7 & 0 & 0 & 56 \\
\hline Aralık & 1 & 2 & 4 & 15 & 29 & 2 & 1 & 0 & 56 \\
\hline Toplam & 27 & 28 & 41 & 178 & 326 & 61 & 10 & 1 & 672 \\
\hline $\operatorname{Oran}(\%)$ & 4,02 & 4,17 & 6,10 & 26,49 & 48,51 & 9,08 & 1,49 & 0,15 & 100 \\
\hline
\end{tabular}

Tablo 10. Aylık PNI metodu görülme sayıları ve oranları

\begin{tabular}{llllll}
\hline AYLAR & $\begin{array}{l}\text { Normal } \\
\text { ve } \\
\text { Üzeri }\end{array}$ & $\begin{array}{l}\text { Hafif } \\
\text { Kuraklık }\end{array}$ & $\begin{array}{l}\text { Orta } \\
\text { Şiddetli } \\
\text { Kuraklık }\end{array}$ & $\begin{array}{l}\text { Şiddetli } \\
\text { Kuraklık }\end{array}$ & Toplam \\
\hline Ocak & 31 & 7 & 4 & 14 & $\mathbf{5 6}$ \\
Şubat & 27 & 11 & 8 & 10 & $\mathbf{5 6}$ \\
Mart & 32 & 8 & 4 & 12 & $\mathbf{5 6}$ \\
Nisan & 32 & 4 & 2 & 18 & $\mathbf{5 6}$ \\
Mayis & 27 & 8 & 4 & 17 & $\mathbf{5 6}$ \\
Haziran & 29 & 5 & 4 & 18 & $\mathbf{5 6}$ \\
Temmuz & 24 & 4 & 4 & 24 & $\mathbf{5 6}$ \\
Ağustos & 22 & 5 & 2 & 27 & $\mathbf{5 6}$ \\
Eylül & 28 & 3 & 5 & 20 & $\mathbf{5 6}$ \\
Ekim & 26 & 6 & 10 & 14 & $\mathbf{5 6}$ \\
Kasim & 32 & 5 & 3 & 16 & $\mathbf{5 6}$ \\
Aralik & 33 & 1 & 6 & 16 & $\mathbf{5 6}$ \\
\hline Toplam & $\mathbf{3 4 3}$ & $\mathbf{6 7}$ & $\mathbf{5 6}$ & $\mathbf{2 0 6}$ & $\mathbf{6 7 2}$ \\
Oran(\%) & $\mathbf{5 1 , 0 4 \%}$ & $\mathbf{9 , 9 7 \%}$ & $\mathbf{8 , 3 3 \%}$ & $\mathbf{3 0 , 6 5 \%}$ & $\mathbf{1 0 0 \%}$ \\
& & & & & \\
\hline
\end{tabular}




\subsubsection{Trend analiz sonuçları}

Mann-Kendall trend testi kullanılarak SPI ve PNI verilerinin eğilim analizi yapılmıștır. SPI ve PNI verilerinin eğilim analizi aylık sonuçları Tablo 11 'de, yıllık ve mevsimlik sonuçları ise Tablo 12 'de verilmiştir.

Tablo 11. SPI ve PNI sonuçlarının aylık periyotlarda MK-Z değerleri

17030-Samsun

\begin{tabular}{ccccccccccccc}
\hline Aylar & Ocak & Şubat & Mart & Nisan & Mayıs & Haziran & Temmuz & Ağustos & Eylül & Ekim & Kasım & Aralık \\
MK-Z & 0,11 & $-0,09$ & 0,56 & $-1,03$ & $-0,26$ & 0,891 & 1,336 & 0,615 & $-0,37$ & 0,325 & 0,304 & 0,17 \\
\hline
\end{tabular}

Tablo 12. SPI ve PNI sonuçlarının yıllık ve mevsimlik periyotlarda MK-Z değerleri

\begin{tabular}{llllll}
\hline \multicolumn{7}{c}{ 17030-Samsun } \\
\hline & Yıllık & Kiş & İlkbahar & Yaz & Sonbahar \\
MK-Z & 1,336 & $-0,092$ & $-0,113$ & 2,361 & 0,007 \\
\hline
\end{tabular}

Tablo 11, 12 incelediğinde; Şubat, Nisan, Mayıs ve Eylül aylarında azalan yönde değerler görülürken diğer tüm aylarda artan yönde eğilim görülmektedir. MK-Z değerleri hem SPI hem de PNI yöntemlerine göre aynı değerlere sahiptir. 12-aylık incelemelerde kuraklık indekslerinin artan yönde eğilim gösterdiği fakat bu eğilimin güven aralıkları dişında diğer bir değişle $\mathrm{H}_{0}$ hipotezinin kabul edildiği, trendin olmadığ bölgede olduğu tespit edilmiştir. 3-aylık incelemelerde ise Aralık-Mayıs ayalarında azalan yönde eğilimler, Haziran-Kasım aylarında ise artan eğilimler tespit edilmiştir. Tüm bu analizlerden sadece Haziran-Temmuz ve Ağustos aylarının değerlendirildiği kısımda belirlenen eğilim değeri istatistiksel olarak anlamlıdır. Kuraklık değerlerinin MK-Z değeri güven aralığının \%95'lik sınır değerini $(1,96)$ aşmaktadır. Tüm bu sonuçlar SPI ve PNI yöntemlerin birbiriyle uyumlu olduğunu yanı bir önceki sonuç değeri ve bir sonraki sonuç değeri arasındaki değişimin (sayısal büyüklüğü ihmal edilerek) aynı olduğunu gösterir.

\section{Tartışma ve Sonuç}

Bu çalışmada Orta Karadeniz'de yer alan Samsun Meteoroloji istasyonu yağış verileri (1960-2015 yılları arası 56 yıl) kullanılarak SPI ve PNI metotlarıyla kuraklık, aylık, 3-aylık ve 12-aylık periyotlarda olarak incelenmiștir. Kuraklığı sınıflayan aralıkların bazı yıllarda ve aylarda birbirleriyle uyum içerisinde olduğu tespit edilmiștir. Yapısı ve kullanıșı daha basit olan PNI metodu değerlendirmesi sinıflandırmada ayrımları düşük bir duyarlılık çerçevesinde sağlarken, SPI değerlendirmesi özellikle standart sapmayı dikkate alarak sonuçları sınıflandırdığı için daha yüksek duyarlılıkta sonuçlar/öneriler verdiği tespit edilmiştir. Ayrıca indeks değerlerinin trend analizi aylık, 3aylık ve 12-aylık periyotlarda incelenmiştir. SPI ve PNI yöntem sonuçlarının eğilimlerinin birbiriyle tam uyumlu olduğu, MK yönteminin eğilimi belirlerken zaman serisindeki sayısal büyüklükler yerine sıra sayısına göre eğilimi belirlediği tespit edilmiştir. Kuraklık indeksleriyle ve MK yöntemiyle yapılan analizlerin bölgedeki kuraklı belirtisinin normale yakın ve normal üzeri olduğu tespit edilmiştir (Tablo 5-10).

MK yöntemi kullanılarak SPI ve PNI indislerinin eğilimi belirlerken, indislerin sayısal büyüklüğü ihmal edilip serideki verilerin sırasına göre hesap yapıldığı görülmektedir (Denklem 4). Diğer bir deyişle bir önceki indisin bir sonraki indis değerine göre eğilimler belirlenmektedir. SPI ve PNI yöntemlerinde elde edilen indislerin dahil oldukları sınıflar farklılık gösterse de indislerin kendi aralarındaki sıralanmalarında büyüklük sırası değișmediği için analiz sonuçları değișmemiștir ve tek tabloda verilmiştir (Tablo 11, 12). 


\section{Kaynakça}

[1] Efe, B., Özgür, E. 2014. Standart Yağıș İndeksi (SPI) ve Normalin Yüzdesi Metodu (PNI) ile Konya ve Çevresinin Kuraklık Analizi, II. Uluslararası Katılıml Kuraklık ve Çölleşme Sempozyumu, 16 - 18 Eylül, Konya,1-6.

[2] Solomon, S., Qin, D., 2007. Summary for Policymakers, in Climate Change 2013 - The Physical Science Basis, Intergovernmental Panel on Climate Change, Cambridge University Press, cilt. 53(9), s 130.

[3] Anonim, 2018. http://www.milliyet.com.tr/ulkedeasiri-sicaktan-167-kisi-oldu-dunya-2453932/. (Erișim Tarihi: 29-08-2018).

[4] Anonim, 2015.http://www.ntvmsnbc.com/id/ 24998660/\%3C . (Erişim Tarihi: 15-12-2015).

[5] Jenkins, K., Warren, R., 20125. Quantifying the impact of climate change on drought regimes using the Standardised Precipitation Index, Theor. Appl. Climatol., Cilt. 120, no. 1-2, s. 41-54.

[6] Osuch, M., Romanowicz, R. J., Lawrence, D., Wong, W. K. 2016. Trends in projections of standardized precipitation indices in a future climate in Poland, Hydrol. Earth Syst. Sci., Cilt. 20, no. 5, s. 1947-1969.

[7] Oğuztürk, G. ve Yıldız, O., 2014. Drought Analysis for Different Time periods in the city of Kirıkkale. International Journal of Engineering Research and Development, Cilt. 6, no. 2. s. 1-7.

[8] Selçuk, D. 2017. Kızılırmak Havzasında hidrometeorolojik parametrelerle kuraklık analizi ve tahmini, Ondokuz Mayıs Üniversitesi, Fen Bilimleri Enstitüsü, Yüksek Lisans Tezi, 122s. Samsun.

[9] Hezarani, A., B., 2018. Farklı Kuraklık Analiz Yöntemlerinin Yeşilırmak Havzasında Irdelenmesi. Ondokuzmayıs Üniversitesi, Fen Bilimleri Enstitüsü, Doktora Tezi, 184s, Samsun

[10] Wang, H., Pan, Y., Chen, Y., ve Ye, Z., 2017. Linea trend and abrupt changes of climate indices in the arid region of northwestern China, Atmos. Res., cilt. 196, s 108-118. DOI 10.1016/j.atmosres.2017.06.008

[11] Kaczmarek, V., Strzepek Z., Somlyody, K. M., Priazhinskaya, L., 1996. Water Resources Management in the Face of Climatic. Dordrecht, The Netherlands:/Hydrologic Uncertainties, Water science and technology library, Kluwer Academic Publisher, London, 397s.

[12] Alexander L. V. vd., 2006. Global observed changes in daily climate extremes of temperature and precipitation, J. Geophys. Res. Atmos., Cilt. 111, no. 5, s. 1-22. DOI: 10.1029/2005JD006290

[13] Bartholy, J., Pongracz, R. 2007. Regional analysis of extreme temperature and precipitation indices for the Carpathian Basin from 1946 to 2001, Glob. Planet. Change, Cilt. 57, no. 1-2, s. 83-95. DOI: 10.1016/j.gloplacha.2006.11.002

[14] Brázdil, R., Trnka, M., Dobrovolný, P., Chromá, K. Hlavinka, P. Zcaron Z., 2009. Variability of droughts in the Czech Republic, 1881-2006, Theor. Appl. Climatol., Cilt. 97, no. 3-4, s. 297-315. DOI 10.1007/s00704-008-0065-x

[15] Kiktev, D. B., Caesar, J. Alexander, L. 2009. Temperature and precipitation extremes in the second half of the twentieth century from numerica modeling results and observational data, Izv. Atmos. Ocean. Phys., Cilt. 45, no. 3, s. 284-293. DOI: $10.1134 /$ S0001433809030025

[16] Somorowska, U., 2009. Increase in the hydrological drought risk in different geographical regions of Poland in the 20th century," Prace i Studia Geograficzne, 43, 97-114.

[17] Dai, A., 2011. Drought under global warming: A review, Wiley Interdiscip. Rev. Clim. Chang., Cilt. 2, no. 1 , s. 45-65. DOI: $10.1002 /$ wcc.81

[18] Seneviratne, C. M., vd., 2012. Changes in climate extremes and their impacts on the natural, A Special. Cambridge, UK and New York, USA: Cambridge University Press, New York, 290s.

[19] IPCC, 2019. Managing the Risks of Extreme Events and Disasters to Advance Climate Change Adaptation, in: A Special Report of Working Groups I and II of the Intergovernmental Panel on Climate Change.https://www.ipcc.ch/site/assets/uploads/2 018/03/SREX_Full_Report-1.pdf. (Erișim Tarihi: 0801-2019).

[20] IPCC 2019, Climate Change 2014: Impacts, Adaptation, and Vulnerability, Part A: Global and Sectoral Aspects, in: Contribution of Working Group II to the Fifth Assessment Report of the Intergovernmental Panel on Climate Change https://www.ipcc.ch/report/ar5/wg2/(Erişim Tarihi: 08-01-2019).

[21] Keskin, A. Ü., Beden, N., Demir, V., 2018. Analysis of Annual, Seasonal and Monthly Trends of Climatic Data: A Case Study of Samsun, E-Journal New World Sci. Acad., Cilt. 13, no. 3, s. 51-70.

[22] Tatli, H. 2014. Statistical complexity in daily precipitation of NCEP/NCAR reanalysis over the Mediterranean Basin, Int. J. Climatol., Cilt. 34, no. 1, s. 155-161. DOI: 10.1002/joc.3673

[23] Bayazıt, M. ve Oğuz E.B. 2013. Mühendisler için istastistik, Birsen yayınevi, İstanbul, 197s

[24] Yacoub, E., ve Tayfur, G., 2017. Evaluation and Assessment of Meteorolical Drought by Different Methods in Trazza Region, Mauritania, Water Resources Management. Cilt.31, s. 825-845.

[25] Mckee, T. B., Doesken, N. J., Kleist, J., 1993. The relationship of drought frequency and duration to time scales, AMS 8th Conf. Appl. Climatol., 1722.0cak.1993, California, 179-184.

[26] Willeke, G., Hosking, J. R. M., Wallis, J. R., Guttman, N. B., 1994. The National Drought Atlas, Institute for Water Resources Report 94-NDS-4, U.S. Army Corps of Engineers, Washington, 587s.

[27] Mann, H. B., 1945. Nonparametric Tests Against Trend, Econometrica, Cilt. 13, no. 3, s. 245-259. DOI: $10.2307 / 1907187$

[28] Kendall, M. G., 1975. Rank Correlation Methods. Charles Griffin, London, 271s

[29] Yue, S., Pilon, P., Cavadias, G., 2002. Power of the Mann-Kendall and Spearman's rho tests for detecting monotonic trends in hydrological series, J. Hydrol., Cilt. 259, no. 1-4, s. 254-271. DOI: 10.1016/S00221694(01)00594-7

[30] Kolmogorov, A.N., 1933. Sulla Determinazione Empirica di Una Legge di Distribuzione, Giornale dell'Istituto Italiano Degli Attuari, Cilt. 4, s. 83-91. DOI: $10.12691 /$ ajams-1-1-2 
DEU FMD 22(64), 107-116, 2020

[31] Smirnov, N.V., 1939. Estimate of deviation between empirical distribution functions in two independent samples. Bull Moscow University, Cilt. 2, s. 3-16.

[32] Yıldırım, N., 2013. Normal Dağılım için Uyum İyiliği Testleri ve Bir Simülasyon Çalışması. Gazi Üniversitesi, Fen Bilimleri Enstitüsü, Yüksek Lisans Tezi, 60s, Ankara.

[33] Svoboda, M., Hayes, M., Wood, D., 2012. Standardized Precipitation Index User Guide. World Meteorological Organization (WMO-No. 1090), Geneva, 24s. 